\title{
The diagnosis of colorectal cancer in patients with symptoms: finding a needle in a haystack Robert H Fletcher
}

Address: Harvard Medical School, Boston, Massachusetts, USA

Email: Robert H Fletcher - Robert_Fletcher@hms.harvard.edu

Published: 17 April 2009

BMC Medicine 2009, 7:18 doi:10.1186/174|-7015-7-18
Received: 19 March 2009

Accepted: 17 April 2009

This article is available from: http://www.biomedcentral.com/I74I-7015/7/18

(c) 2009 Fletcher; licensee BioMed Central Ltd.

This is an Open Access article distributed under the terms of the Creative Commons Attribution License (http://creativecommons.org/licenses/by/2.0), which permits unrestricted use, distribution, and reproduction in any medium, provided the original work is properly cited.

\begin{abstract}
Patients often see primary care physicians with symptoms that might signal colorectal cancer but are also common in adults without cancer. Physicians and patients must then make a difficult decision about whether and how aggressively to evaluate the symptom. Favoring referral is that missed diagnoses lead to unnecessary testing, prolonged uncertainty, and continuing symptoms; also, the physician will suffer chagrin. It is not clear that diagnostic delay leads to progression to a more advanced stage. Against referral is that proper evaluation includes colonoscopy, with attendant inconvenience, discomfort, cost, and risk. The article by Hamilton et al, published this month in BMC Medicine, provides strong estimates of the predictive value of the various symptoms and signs of colorectal cancer and show how much higher predictive values are with increasing age and male sex. Unfortunately, their results also make clear that most colorectal cancers present with symptoms with low predictive values, $<1.2 \%$. Models that include a set of predictive variables, that is, risk factors, age, sex, screening history, and symptoms, have been developed to guide primary prevention and clinical decision-making and are more powerful than individual symptoms and signs alone. Although screening for colorectal cancer is increasing in many countries, cancers will still be found outside screening programs so primary care physicians will remain at the front line in the difficult task of distinguishing everyday symptoms from life-threatening cancer.
\end{abstract}

\section{Commentary}

Patients often see primary care physicians for symptoms that might signal colorectal cancer, raising difficult questions. Which patients should be evaluated? How aggressively should they be worked up? If another cause for the symptom is found, such as hemorrhoids for rectal bleeding, should that set the matter to rest or should a cancer diagnosis still be pursued?

Table 1 lists 15 symptoms of colorectal cancer that have been suggested in textbooks and supported by research evidence [1]. Unfortunately, many of these same symptoms, especially constipation and fatigue, are common in patients who do not have colorectal cancer. True, some clinical presentations, such as bowel obstruction or severe abdominal or rectal pain, are sufficiently unusual and dramatic events that they would prompt quick evaluation in any case. However, most symptoms of colorectal cancer are not so compelling. As a result, first-contact physicians are in the familiar position of looking for a needle in a haystack.

The stakes are high on either side of the decision. If the diagnosis is missed the patient will undergo unnecessary testing, prolonged uncertainty, and continuing symptoms until the diagnosis is finally made. The clinician will suffer 
Table I: Presenting symptoms and signs for 194 patients with colorectal cancer

\begin{tabular}{|c|c|}
\hline Symptom & Percentage of patients \\
\hline Fecal occult blood test positive & 77 \\
\hline Rectal bleeding & 58 \\
\hline Anemia* & 57 \\
\hline Abdominal pain & 52 \\
\hline Weight loss & 39 \\
\hline Anorexia & 27 \\
\hline Constipation & 27 \\
\hline Altered stools & 25 \\
\hline Fatigue & 25 \\
\hline Diarrhea & 22 \\
\hline Nausea and vomiting & 22 \\
\hline Tenesmus & 8 \\
\hline Mucus in stools & 6 \\
\hline Rectal pain & 5 \\
\hline Obstruction & 4 \\
\hline
\end{tabular}

Adapted from Majumdar et al. [I].

*Anemia $=$ a hemoglobin of $<13.4 \mathrm{~g} / \mathrm{dl}$ in men or $<12.3 \mathrm{~g} / \mathrm{dl}$ in women.

chagrin [2] and in some settings he or she might also worry about malpractice claims. On the other hand, proper evaluation, which involves complete visualization of the large bowel by colonoscopy, is a big undertaking, with the inconvenience of a day off work, the discomfort of bowel cleansing if not the procedure itself, financial costs to the patients or society, and a small risk of perforation, bleeding, or other complications [3].

Does diagnostic delay allow colorectal cancer to progress from a local to advanced stage, diminishing the possibility of cure? One might think so but the evidence is mixed and for the most part against this possibility $[1,4-6]$. The relationship between diagnostic delay and cancer stage or survival is at the very least complex. For example, a study of 777 consecutive colorectal cancer patients found that shorter duration of symptoms was associated with advanced tumor stage [4]. This makes sense because estimates of the transition time from localized to advanced colorectal cancers is measured in years, much longer than the time from symptoms to diagnosis in most patients. Also, advanced cancers causing bowel obstruction would be evaluated promptly while some slow-growing, localized tumors may not declare themselves (perhaps with systemic symptoms such as fatigue or weight loss) for many months. Therefore, while the other consequences of diagnostic delay are certainly in play, progression to more advanced stage may not be.

The article by Hamilton et al, published this month in BMC Medicine, advances the evidence base for early diagnosis of colorectal cancer [7]. The investigators were fortunate to have access to a large database of patients in general practices in the UK, with data on 23 candidate symptoms and signs of colorectal cancer (or surrogates for some of them, such as drugs prescribed for constipation). The authors calculated likelihood ratios for symptoms and signs from data on 5477 cases of colorectal cancer and controls matched for age, sex, and site. They then estimated the positive predictive values of these symptoms and signs by applying their likelihood ratios to national data on the incidence of colorectal cancer, using Bayes' theorem: prior odds $\times$ likelihood ratio $=$ posterior odds (where the national incidence data was used to derive prior odds). This approach is sound if one is willing to assume that patients in the general practices and in the nation as a whole are comparable. Given the size of the database, the authors could describe the predictive value of each symptom and sign with clinically useful precision, even though colorectal cancer is uncommon. The authors analyzed the data and described their results with an admirable grasp of both the scientific issues and the clinical realities of colorectal cancer presentation in general practice.

The Hamilton study identified predictive variables that have long been part of clinical lore and more recently confirmed by clinical research. With their large sample size, the authors were able to go further to show how powerfully age, and to a lesser extent sex, affect predictive values for this condition. However, the authors admit that their study could not solve the problem of early diagnosis, mainly because most patients presented with symptoms with low predictive values. The presenting symptoms for $73 \%$ of colorectal cancer patients had predictive values of $<1.2 \%$. Although two symptoms (rectal bleeding and change in bowel habits) had relatively high positive predictive values, they were uncommon. Therefore, physicians must still wrestle with referral decisions for the larger proportion of patients with symptoms only weakly associated with colorectal cancer.

As the authors suggest, a set of variables may predict better than individual symptoms and signs taken one at a time. 
Predictive models for colorectal cancer have been developed [8-12]. Some of these models are designed to guide primary prevention and include age and behavioral risk factors such as smoking, diet, obesity, and exercise. Others are for clinical cancer detection and include symptoms and signs, as well as age. Models posted on the US National Institutes of Health and Harvard Medical School's public websites $[11,12]$ take screening history into account, as they should in settings such as the US where colorectal cancer screening has been widely practiced for years. Unfortunately, no model so far, whether for preventive care or clinical diagnosis, includes all of these predictors. Even if one did, it might not produce strong enough odds ratios to be as helpful in individual patients as in groups of patients $[13,14]$.

It is always difficult to choose a reasonable threshold for further testing. Hamilton et al. assert that most would agree that positive predictive values in the $2.4 \%$ to $4.5 \%$ range, seen with rectal bleeding in men over 60 years, are high enough to warrant investigation whereas positive predictive values below 1.5\% (as seen with constipation, diarrhoea, abdominal pain, and loss of weight) reflect 'low-risk symptoms'. Other general practitioners in the UK, or referral physicians, may have different opinions. Care with high costs and low yield may be considered worthwhile in one country but out of reach or profligate in others. Also, the implementation of predictive models are compromised to the extent that physicians feel uncomfortable missing any cancers, no matter how low the probability, and so make decisions using 'clinical judgment' even when powerful predictive models exist $[15,16]$.

Will screening programs make the clinical diagnosis of colorectal cancer a challenge of the past? Screening for colorectal cancer has been shown to be effective and is being implemented in many countries [17]. In the US, nearly two-thirds of adults are being screened [18] and colonoscopy is becoming the test of choice [19]. Other countries have for the most part chosen fecal occult blood testing for average risk adults [17]. Is it not likely that in the future screening will find most cancers, or lead to their prevention by removing polyps, so that the need for clinical diagnosis will all but disappear. Probably not because of the net effects of insensitive tests, refusal to be screened, and new cancers in the interval between screenings. Therefore, primary care physicians will remain at the front line in the difficult task of distinguishing everyday symptoms from life-threatening cancer.

\section{References}

I. Majumdar SR, Fletcher RH, Evans AT: How does colorectal cancer present? Symptoms, duration, and clues to location. Am J Gastroenterol 1999, 94:3039-3045.

2. Feinstein AR: The 'chagrin factor' and qualitative decision analysis. Arch Intern Med I 985, I 45: I 257-1259.
3. Gatto NM, Frucht H, Sundararajan V, Jacobson JS, Grann VR, Neugut Al: Risk of perforation after colonoscopy and sigmoidoscopy: A population-based study. J Natl Cancer Inst 2003, 95:230-236.

4. Mulcahy HE, O'Donoghue DP: Duration of colorectal cancer symptoms and survival: the effect of confounding clinical and pathological variables. Eur J Cancer 1997, 33:|46|- 467.

5. Maguire A, Porta M, Malats N, Gallen M, Pinol JL, Fernandez E: Cancer survival and the duration of symptoms. An analysis of possible forms of the risk function. Eur J Cancer 1994, 30A:785-792.

6. Gellad ZF, Almirall D, Provenzale D, Fisher DA: Time from Positive Screening Fecal Occult Blood Test to Colonoscopy and Risk of Neoplasia. Dig Dis Sci 2008 in press.

7. Hamilton W, Lancashire R, Sharp D, Peters T, Cheng K, Marshall T: The risk of colorectal cancer with symptoms at different ages and between the sexes: a case-control study. BMC Medicine 2009, 7:17.

8. Hamilton W: Derivation of a score for identifying colorectal cancer in primary care. Gut 2007, 56(Suppl 2):A46.

9. Driver JA, Gaziano JM, Gelber RP, Lee I-M, Buring JE, Kurth T: Development of a risk score for colorectal cancer in men. Am J Med 2007, 1 20:257-263.

10. Selvachandran SN, Hodder RJ, Ballal MS, Jones P, Cade D: Prediction of colorectal cancer by a patient consultation questionnaire and scoring system: a prospective study. Lancet 2002, 260:278-283.

II. Colorectal Cancer Assessment Tool [http://www.cancer.gov/ colorectalcancerrisk/]

12. Disease Risk Index [http://www.diseaseriskindex.harvard.edu]

13. Wald NJ, Hackshaw AK, Frost CD: When can a risk factor be sued as a worthwhile screening test? $B M]$ | 1999, 3 I 9: I562-I565.

14. Ware $\mathrm{JH}$ : The limitations of risk factors as prognostic tools. $\mathrm{N}$ Engl J Med 2006, 355:2615-2617.

15. Fletcher RH: Commentary. ACP J Club 2003, 8: 185.

16. Cameron $C$, Naylor $C D$ : No impact from active dissemination of the Ottawa Ankle Rules: further evidence of the need for local implementation of practice guidelines. CMAJ 1999, 160:1165-1168

17. Benson VS, Patnick J, Davies AK, Nadel MR, Smith RA, Atkin WS: International Colorectal Cancer Screening Network. Int J Cancer 2008, I22:1357-1367.

18. Joseph DA, Rim SH, Seeff LC: Use of colorectal cancer tests United States, 2004, 2006. MMWR Morb Mortal Wkly Rep 2002, 57:253-258.

19. Meissner HI, Breen N, Klabunde CN, Vernon SW: Patterns of colorectal cancer screening uptake among men and women in the United States. Cancer Epidemiol Biomarkers Prev 2006, 15:389-394.

\section{Pre-publication history}

The pre-publication history for this paper can be accessed here:

http://www.biomedcentral.com/1741-7015/7/18/prepub

Publish with Biomed Central and every scientist can read your work free of charge

"BioMed Central will be the most significant development for disseminating the results of biomedical research in our lifetime. "

Sir Paul Nurse, Cancer Research UK

Your research papers will be:

- available free of charge to the entire biomedical community

- peer reviewed and published immediately upon acceptance

- cited in PubMed and archived on PubMed Central

- yours - you keep the copyright

Submit your manuscript here:

http://www.biomedcentral.com/info/publishing_adv.asp
BioMedcentral 